\title{
NT-PROBNP AND ECHOCARDIOGRAPHIC PARAMETERS IN PATIENTS WITH ACUTE HEART FAILURE
}

\author{
Radek Pudil ${ }^{1}$, Miloš Tichýr ${ }^{2}$ Rudolf Praus ${ }^{1}$, Václav Bláha ${ }^{3}$, Jan Vojáček $^{1}$
}

Charles University in Prague, Faculty of Medicine in Hradec Králové and University Hospital Hradec Králové, Czech Republic: ${ }^{\text {st }}$ Department of Medicine - Division of Cardiology ${ }^{1}$; Institute of Clinical Biochemistry ${ }^{2}$; University of Defence Brno, Faculty of Military Health Sciences, Hradec Králové, Czech Republic: Department of AD Systems ${ }^{3}$

Summary: Aim. The aim of this study was to analyse the relation between clinical, haemodynamic and X-ray parameters and plasma NT-proBNP level in pts with symptoms of left ventricular dysfunction. Methods. The plasma NT-proBNP levels, chest x-ray, transthoracic 2-d and Doppler echocardiography were performed at the time of admission in a group of 96 consecutive patients (mean age $68 \pm 11$ years) with symptoms of acute heart failure. NT-proBNP levels were assessed with the use of commercial tests (Roche Diagnostics). Results. All patients have significant increase in NT-proBNP ( 8000 $\pm 9000 \mathrm{pg} / \mathrm{mL}$ vs. controls $90 \pm 80 \mathrm{pg} / \mathrm{mL}, \mathrm{p}<0.001$ ). The group of all patients has shown a significant increase in cardiothoracic ratio (CTR, $0.6 \pm 0.1$, vs. $0.4 \pm 0.1, \mathrm{p}<0.001$ ), left atrium diameter (LAD, $4.4 \pm 0.8 \mathrm{~cm}, \mathrm{vs} .3 .5 \pm 0.4 \mathrm{~cm}$, $\mathrm{p}<0.01$ ). Left ventricular ejection fraction (LVEF) was decreased $(37 \pm 15 \%$, vs. $64 \pm 5 \%$, p <0.001). In patients with acute heart failure, NT-proBNP significantly correlated with end-systolic and end-diastolic left ventricle diameters, ejection fraction, vena cava inferior diameter and plasma creatinine levels. Conclusion. Increased plasma NT-proBNP level is influenced by the clinical severity of acute heart failure and correlates with LVEF and IVCD. NT-proBNP can serve as a marker for the clinical severity of the disease.

Key words: B-type natriuretic peptide; Acute heart failure; Clinical symptoms; Ejection fraction; Inferior vena cava.

\section{Introduction}

Synthesis of natriuretic peptides and immune activation represents an important part of the neurohumoral response to heart failure. Brain type natriuretic peptide is released primarily from the ventricles in response to myocyte stretch. It is synthesized as an inactive prohormone that is split into active hormone BNP and the inactive N-terminal fragment (NT-proBNP). BNP has a number of systemic effects, including vasodilation, increased sodium excretion and urinary volume, inhibition of the renin-angiotensin-aldosteron system and sympathetic nervous system $(6,10,19,20)$. The main pathological process resulting in increased synthesis and the BNP release and NT-proBNP is impairment of left ventricular systolic or diastolic function $(2,11,18)$. The plasma NT-proBNP is also an independent prognostic factor (1, $8,12,13,21)$. Therefore, the assessment of natriuretic peptides has been implemented into the ESC and AHA/ACC guidelines for diagnosis and management of heart failure $(9,16)$.

The aim of this study was to analyse the relation between clinical, haemodynamic, and X-ray parameters, and plasma NT-proBNP level in pts with symptoms of left ventricular dysfunction admitted to the intensive care department.

\section{Patients/Material and Methods}

\section{Study population}

The study population consisted of 96 consecutive patients [mean age, 68 (11) years, median 69 yrs, range 22-81 years, 45 women and 51men] with symptoms of left ventricular dysfunction admitted to the Intensive care Department between March and August 2004. The exclusion criteria for this study were acute heart failure in the course of acute myocardial infarction (according to positive cardiac troponin level, presence of chest pain or typical ecg. changes), sepsis, volume overload caused by serious renal and liver disease. Etiology of the heart failure was as follows: primary dilated cardiomyopathy was found in 11 $(11.4 \%)$ patients, valvular disease in $8(8.3 \%)$ patients, whereas the other 79 (75\%) patients suffered from coronary artery disease. Fifty patients $(52.1 \%)$ were diabetics, $63(65.5 \%)$ patients were treated for arterial hypertension (Tab. 1). The therapy consisted of the administration of diuretics, vasodilatation (intravenous administration of nitrates, or oral administration of angiotensin converting enzyme inhibitors, angiotensinogen receptor blockers), and sympatomimetic amines if clinical status of the patient required. 
The investigation conforms with the principles outlined in the Declaration of Helsinki and has been approved by the Ethical Committee of our institution. All patients provided informed consent prior to participation.

\section{Control group}

All healthy individuals [mean (SD) age 47 (17) years, 12 women and 14 men, 4 were over 50 years old] were nonobese, normotensive, and free from acute diseases, and they all denied the use of any drugs during the 4 weeks before the study. They all had normal plasma values for the main plasma indices and, as well as non-pathologic erythrocyte and leukocyte counts and urine analysis. In all of the participants a complete cardiologic examination, including electrocardiogram and echocardiographic investigation (left ventricular ejection fraction $>55 \%$ ), was performed. In the subjects $>50$ years of age, an effort stress test (bicycle ergometry) was performed to exclude asymptomatic heart disease. Cardiac morphology and function were assessed by echocardiography. The control group was recruited from the people examined in our department in preventive programmes.

\section{Blood specimen collection and analysis}

Venous blood samples were obtained after 30 minutes of supine rest position from an indwelling catheter immediately after admission. Blood samples were collected in chilled tubes containing EDTA, immediately placed on ice, and promptly centrifuged. After centrifugation, the plasma was decanted and stored at $-20{ }^{\circ} \mathrm{C}$ until assayed.

Plasma NT-proBNP concentrations were determined by using electrochemiluminiscence sandwich immunoassay (Roche Diagnostics). The assay was performed on the Elecsys System 1010 by the same analyst, who followed the assay manufacturer's recommendations.

\section{Echocardiography}

The transthoracic echocardiography was performed on each patient by the same operator, who was blinded to the humoral data. The measurements for M-mode guided calculation of left ventricular mass (LVM, left ventricular internal end-systolic and end-diastolic dimensions (LVIDs and LVIDd, respectively), interventricular septal wall thickness (IVST), left ventricular posterior wall thickness (PWT), right ventricular internal dimension (RVID) and left atrium diameter (LAD) were performed according to the guidelines of the American Society of Echocardiography (17). Left ventricular mass (LVM) was calculated according to the Devereux formula and indexed to body surface area (7). The presence of left ventricular hypertrophy (LVH) was defined on the basis of an LVMI greater than $>134 \mathrm{~g} / \mathrm{m}^{2}$ body surface area in men or $>110 \mathrm{~g} / \mathrm{m}^{2}$ body surface area in women. For the measurement of IVC diameter, the patients were scanned in the supine position, and the IVC was visualized by a subcostal approach. The diameter was measured within $2 \mathrm{~cm}$ of the right atrium origin of IVC. In cases when the IVC diameter was not stable through pulsation, the diameter was determined by using maximum values of IVC diameter of M-mode technique. Because of acute settings in acute intensive care department, the respiratory variations were not measured.

\section{Cardiothoracic ratio}

Cardiothoracic ratio (CTR) was assessed as the ratio between the maximal transverse diameter of the heart, and the maximal diameter of the thoracic cage, as measured on an AP chest radiograph.

\section{Statistical analysis}

Data are presented as mean \pm SD or as median. Clinical characteristics and haemodynamic data of study population are presented as percentages of dichotomous variables and means \pm SD for continuous variables. Linear regression analysis was performed to assess the relation between plasma NT-proBNP and clinical parameters. Pearson's rank correlation test was performed to evaluate the relationship between NT/proBNP and clinical variables. Potential confounding factors that might significantly contribute to NTproBNP elevation were evaluated by the use of multiple regression analysis.

\section{Results}

\section{Demographic and clinical characteristics of the study population (Tab. 1, 2)}

The most common cause of heart failure in the study population was chronic coronary artery disease; the majo-

Tab. 1: Clinical characteristics and haemodynamic data of the patients at the time of admission.

\begin{tabular}{|l|c|}
\hline Age $(\mathrm{y})$ & $68 \pm 11$ \\
\hline Male $(\%)$ & $51(53.2)$ \\
\hline Etiology of HF & $77(80)$ \\
- CAD (\%) & $65(67.7)$ \\
- previous myocardial infarction (\%) & $11(11.4)$ \\
- dilated cardiomyopathy (\%) & $8(8.3)$ \\
- valvular disease (\%) & $63(65.5)$ \\
\hline Arterial hypertension (\%) & $50(52.1)$ \\
\hline Diabetes $(\%)$ & $47(49)$ \\
\hline Smoking $(\%)$ & $6.23 \pm 0.7$ \\
\hline Total cholesterol $(\mathrm{mmol} / \mathrm{mL})$ & $4.2 \pm 0.8$ \\
\hline LDL-cholesterol $(\mathrm{mmol} / \mathrm{mL})$ & $144.8 \pm 4445$ \\
\hline Serum creatinine $(\mu \mathrm{mol} / \mathrm{mL})$ & \\
\hline Haemodynamic data & $97.0 \pm 24.9$ \\
- heart rate (bpm) & $35(36.5)$ \\
- atrial fibrillation $(\%)$ & $141.3 \pm 31.7$ \\
- systolic blood pressure $(\mathrm{mmHg})$ & $82.8 \pm 15.0$ \\
\hline
\end{tabular}

Data are expressed as mean and SD or in percents, $\mathrm{CAD}=$ coronary artery disease, LDL-C = low density cholesterol, $\mathrm{SBP}=$ systolic blood pressure, $\mathrm{DBP}=$ diastolic blood pressure, $H R=$ heart rate. 
rity of these patients had previous myocardial infarctions. Eighty percent of all patients had at least three risk factors. The mean age for the entire group of patients was significantly higher vs. controls $(68 \pm 11$ vs. $47 \pm 17$ years, $\mathrm{p}<$

Tab. 2: Characteristics of the controls and subgroups of study population.

\begin{tabular}{|l|c|c|c|}
\hline & Controls & $\begin{array}{c}\text { Patients } \\
(\mathrm{N}=26)\end{array}$ & $\begin{array}{c}\mathrm{p} \\
(\mathrm{N}=96)\end{array}$ \\
\hline Age $(\mathrm{y})$ & $47 \pm 17$ & $68 \pm 11$ & $<0.01$ \\
\hline NT-proBNP $(\mathrm{pg} / \mathrm{mL})$ & $90 \pm 80$ & $8000 \pm 9000$ & $<0.001$ \\
\hline CTR & $0.4 \pm 0.1$ & $0.6 \pm 0.1$ & $<0.001$ \\
\hline LAD $(\mathrm{cm})$ & $3.5 \pm 0.4$ & $4.4 \pm 0.7$ & $<0.001$ \\
\hline RVID $(\mathrm{cm})$ & $2.6 \pm 0.3$ & $2.85 \pm 0.45$ & $<0.05$ \\
\hline IVST $(\mathrm{cm})$ & $1.1 \pm 0.1$ & $1.2 \pm 0.1$ & $<0.05$ \\
\hline LVIDs $(\mathrm{cm})$ & $3.5 \pm 0.4$ & $4.4 \pm 0.1$ & $<0.001$ \\
\hline LVIDd $(\mathrm{cm})$ & $5.1 \pm 0.4$ & $6.4 \pm 0.6$ & $<0.001$ \\
\hline LVEF $(\%)$ & $63.6 \pm 5.1$ & $37.1 \pm 15.4$ & $<0.001$ \\
\hline PWT $(\mathrm{cm})$ & $1.1 \pm 0.1$ & $1.1 \pm 0.1$ & $<0.05$ \\
\hline IVCD $(\mathrm{mm})$ & $15.4 \pm 1.9$ & $22.2 \pm 3.4$ & $<0.001$ \\
\hline LVMI $\left(\mathrm{g} / \mathrm{m}^{2}\right)$ & $121 \pm 12$ & $165 \pm 41$ & $<0.01$ \\
\hline Pl. creatinine $(\mu \mathrm{mol} / \mathrm{l})$ & $76 \pm 31$ & $144 \pm 44$ & $<0.01$ \\
\hline
\end{tabular}

$\mathrm{CTR}=$ cardiothoracic ratio, $\mathrm{LAD}=$ left atrium diameter, RVD $=$ right ventricle internal diameter, IVST $=$ interventricular septum thickness, LVIDs = left ventricular internal end-systolic diameter, LVIDd = left ventricular internal enddiastolic diameter, $\mathrm{LVEF}=$ left ventricular ejection fraction, PWT $=$ posterior wall thickness, IVCD $=$ inferior vena cava inferior diameter, $\mathrm{LVMI}=$ left ventricular mass index.

Tab. 3: Relationship between NT-probrain natriuretic peptide, cardiothoracic ratio, echocardiographic parameters and plasma creatinine level in patients with heart failure at the time of admission.

\begin{tabular}{|l|c|c|}
\hline & \multicolumn{2}{|c|}{ NT-proBNP } \\
\hline & $\begin{array}{c}\text { Pearsons' rank } \\
\text { correl. coeff., } \mathrm{r}\end{array}$ & $\begin{array}{c}\mathrm{p} \\
\text { value }\end{array}$ \\
\hline CTR & 0.18 & $\mathrm{~ns}$ \\
\hline LAD & 0.16 & $\mathrm{~ns}$ \\
\hline RVID & 0.1 & $\mathrm{~ns}$ \\
\hline IVST & 0.003 & $\mathrm{~ns}$ \\
\hline LVIDs & 0.31 & $<0.01$ \\
\hline LVIDd & 0.54 & $<0.01$ \\
\hline LVEF & -0.31 & $<0.01$ \\
\hline PWT & -0.05 & $\mathrm{~ns}$ \\
\hline IVCD & 0.51 & $<0.01$ \\
\hline LVMI & 0.14 & $\mathrm{~ns}$ \\
\hline Creatinine & 0.53 & $<0.01$ \\
\hline
\end{tabular}

$\mathrm{CTR}=$ cardiothoracic ratio, $\mathrm{LAD}=$ left atrium diameter, RVID $=$ right ventricle internal diameter, IVST $=$ interventricular septum thickness, LVIDs = left ventricular internal end-systolic diameter, LVIDd = left ventricular internal enddiastolic diameter, $\mathrm{LVEF}=$ left ventricular ejection fraction, PWT $=$ posterior wall thickness, IVCD = inferior vena cava inferior diameter, LVMI = left ventricular mass index.
0.001). Nine patients were admitted with clinical symptoms of lung oedema, six patients with cardiogenic shock. Fourteen patients died despite the therapy.

\section{Plasma NT-proBNP levels, Killip class, cardiothoracic ratio (Tab. 2) and plasma creatinine level}

The mean plasma NT-proBNP level of the group of all patients was significantly elevated $(8000 \pm 9000 \mathrm{pg} / \mathrm{mL}$, vs. control group $91 \pm 76 \mathrm{pg} / \mathrm{mL}, \mathrm{p}<0.001)$ and significantly increased with the symptoms' severity (Killip class II pts: $6700 \pm 1900$ pg/mL, Killip class III: $9000 \pm 7000$ pg/mL, Killip class IV: $29000 \pm 7000$ pg/mL). All differences were statistically significant $(p<0.01)$. The cardiothoracic ratio of the patient group was significantly increased compared to controls $(0.6 \pm 0.1$ vs. $0.4 \pm 0.1, \mathrm{p}<0.001)$. Linear regression analysis did not show a significant association between NT-proBNP and CTR. The plasma creatinine level in the patient group was significantly elevated compare to the control group ( $145 \pm 45 \mu \mathrm{mol} / 1$ vs. $76 \pm 31 \mu \mathrm{mol} / 1, \mathrm{p}<0.01)$.

\section{Evaluation of the echocardiographic parameters}

Both left ventricular diameters (end-systolic and enddiastolic) were significantly elevated in the entire group of patients $(4.4 \pm 0.1 \mathrm{~cm}$, vs. $3.5 \pm 0.4 \mathrm{~cm}, \mathrm{p}<0.001$, respectively $6.3 \pm 0.6 \mathrm{~cm}$, vs. $5.1 \pm 0.4 \mathrm{~cm}, \mathrm{p}<0.001)$. Ejection fraction, one of the indicators of left ventricular systolic function, was significantly decreased in the entire group of patients $(37 \pm 15 \%$, vs. $64 \pm 5 \%$, p <0.001). Interventricular septum and posterior wall thickness were slightly increased $(1.2 \pm 0.1 \mathrm{~cm}$ vs. $1.1 \pm 0.1 \mathrm{~cm}, \mathrm{p}<0.05$, and $1.1 \pm 0.1 \mathrm{~cm}$, vs. $1.1 \pm 0.1 \mathrm{~cm}, \mathrm{p}<0.05)$. Left ventricular mass index was increased more $\left(165 \pm 41 \mathrm{~g} / \mathrm{m}^{2}\right.$, vs. $\left.121 \pm 12 \mathrm{~g} / \mathrm{m}^{2}, \mathrm{p}<0.01\right)$. Left atrium and right ventricular diameters were higher in all patients compared to control group (LAD: $4.4 \pm 0.7 \mathrm{~cm}$ vs. $3.5 \pm 0.4 \mathrm{~cm}, \mathrm{p}<0.001$, RVD: $2.8 \pm 0.5 \mathrm{~cm}$ vs. $2.6 \pm 0.3$ $\mathrm{cm}, \mathrm{p}<0.05)$. IVC diameter of the entire group of patients was significantly increased $(22.2 \pm 3.4 \mathrm{~mm}$, vs. $15.4 \pm 1.9$ $\mathrm{mm}, \mathrm{p}<0.001)$.

\section{Correlation between plasma NT-proBNP}

and echocardiographic parameters (Tab. 3, Fig. 1-8)

Left ventricle end-systolic and end-diastolic diameters were significantly positively associated with NT-pro BNP level $(r=0.31$, resp. $r=0.54, p<0.01, n$ 96). LVEF was significantly inversely proportional to NT-proBNP level $(r=$ $0.31 ; \mathrm{p}<0.01, \mathrm{n} 96)$. We also found a significant correlation between NT-proBNP and IVCD $(r=0.51, \mathrm{p}<0.01, \mathrm{n} 96)$ and NT-proBNP and plasma creatinine $(r=0.53, \mathrm{p}<0.01, \mathrm{n} 96)$. Other parameters (LVMI, LAD, RVID and CTR) were without significant correlation with NT-proBNP.

\section{Multivariate linear regression analyses}

We performed multiple regression analysis with the aim to evaluate potential confounding factors (age, gender, previous history of heart disease, diabetes mellitus, smoking, hypercholestrolemia) that might significantly contribute to 


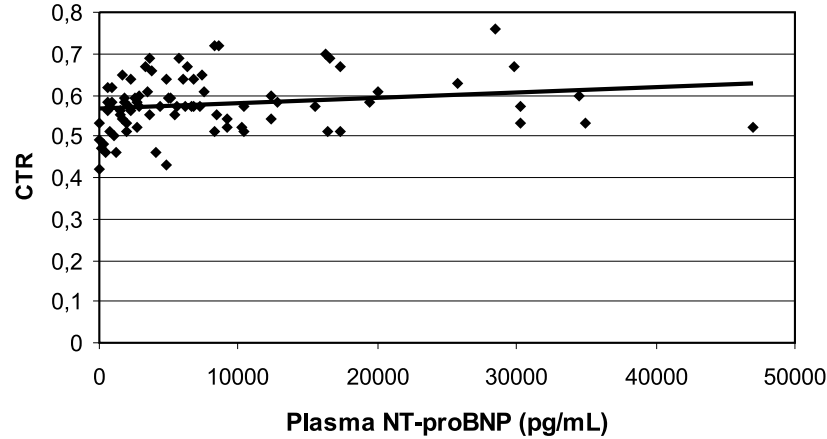

Fig. 1: Linear regression analysis between plasma NTproBNP and cardiothoracic ratio.

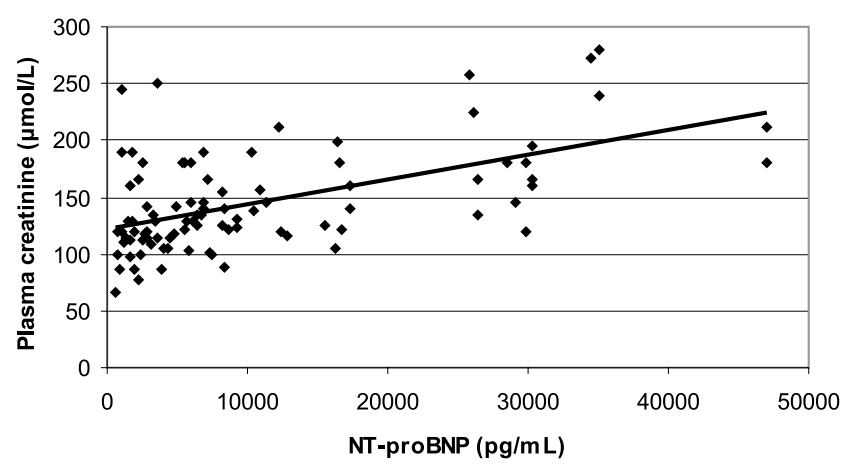

Fig. 2: Linear regression analysis between plasma NTproBNP and plasma creatinine level.

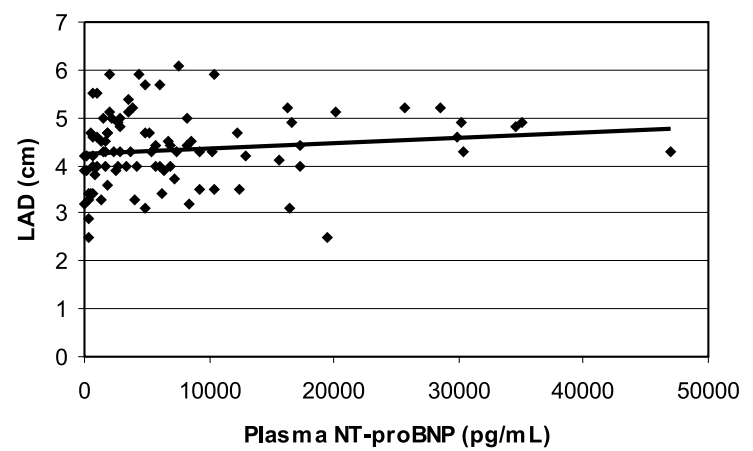

Fig. 3: Linear regression analysis between plasma NTproBNP and left atrium diameter (LAD).

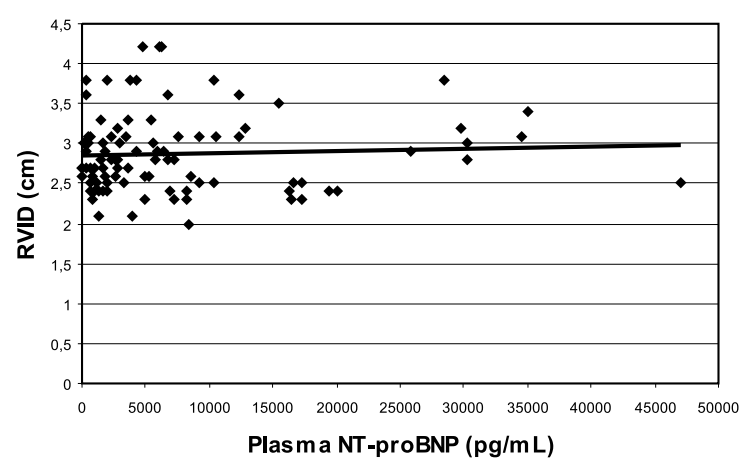

Fig. 4: Linear regression analysis between plasma NTproBNP and right ventricular diameter (RVID).

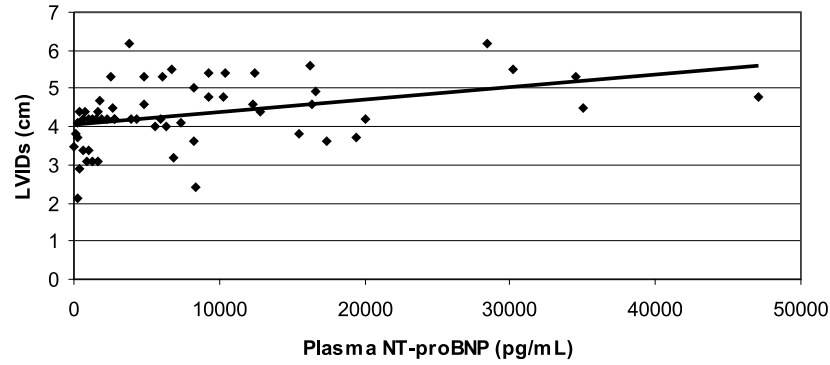

Fig. 5: Linear regression analysis between plasma NTproBNP and systolic left ventricular internal diameter (LVIDs).

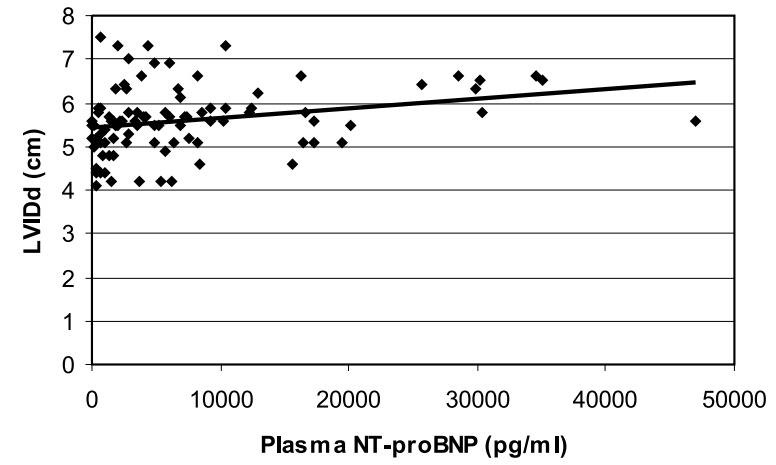

Fig. 6: Linear regression analysis between plasma NTproBNP and end-diastolic left ventricular internal diameter (LVID).

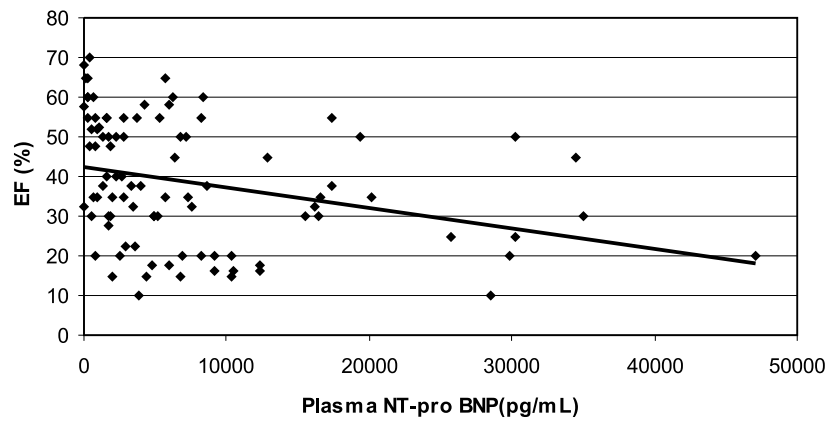

Fig. 7: Linear regression analysis between plasma NTproBNP and ejection fraction (EF, \%).

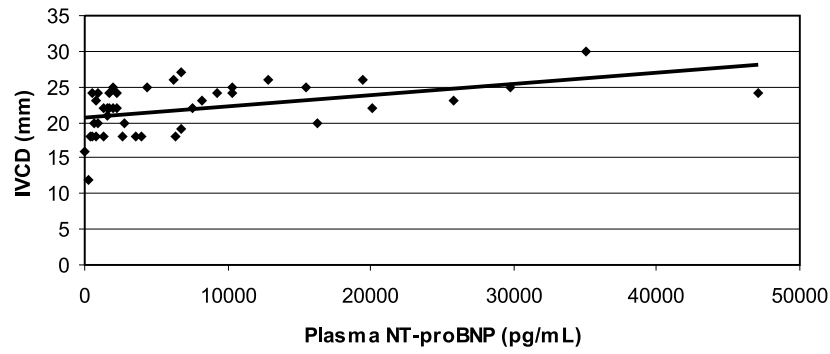

Fig. 8: Linear regression analysis between plasma NTproBNP and inferior vena cava diameter (IVCD, mm). 
NT-proBNP elevation and inferior vena cava diameter. We found significant associations in both IVCD and the female gender $(p<0.05)$, and the association of NT-proBNP with creatinine levels $(p<0.01)$ and previous history of heart failure $(p<0.05)$.

\section{Discussion}

Our study has shown that: (1) acute heart failure was accompanied with significant changes in non-invasive parameters of heart failure (cardio-thoracic ratio, end-systolic and end-diastolic diameters of the left ventricle, left atrium diameter, right ventricle diameter, the decrease in ejection fraction of the left ventricle), (2) the most significant changes were found in NT-proBNP levels. Furthermore, (3) the plasma NT-proBNP correlates not only with left ventricle ejection fraction plasma creatinine level, but also with the inferior vena cava diameter.

Our study was performed as a pilot study and has some limitations: the circulating concentrations of natriuretic peptides are regulated or modified by several physiologic factors, such as circadian variations, age, gender, eating habits, sodium intake and drugs, including diuretics, angiotensin-converting enzyme inhibitors, adrenergic agonists and antagonists. To eliminate the influence of medication the blood samples were taken at the time of admission. Potential confounders weer evaluated with multiple regression analysis.

The previous studies have shown the correlation between ejection fraction of the left ventricle and plasma natriuretic peptide levels $(3,4,14,15,22)$. In our study, we found significant inverse correlation between NT-proBNP and left ventricular ejection fraction.

The increase in both left ventricle diameters can be explained by volume and pressure overload of the left ventricle. In this study we observed that inferior vena cava (IVC) diameter was increased in all patients at the time of admission. It has been shown, that inferior vena cava diameter can reflect volume overload. Recent studies have shown that plasma natriuretic peptide levels can be influenced by left ventricle hypertrophy. Yamamoto et al. (24) showed the slight but significant increase in plasma natriuretic peptide levels in patients with left ventricle hypertrophy and hypertrophic cardiomyopathy. In our study, the increase in plasma NT-proBNP level was extremely high, and we did not find any significant association between plasma NT-proBNP levels and the left ventricle mass index.

The potential clinical use of assays for natriuretic peptides (especially BNP and NT-proBNP) for detection of left ventricular systolic and/or diastolic dysfunction has been confirmed more recently $(5,23,25)$. The ESC Guidelines for diagnosis and treatment of chronic heart failure recommend that cardiac natriuretic peptide assessment should be included in the first step of the algorithm for the diagnosis of HF along with electrocardiography and chest x-rays. According to these guidelines, negative natriuretic peptide level makes diagnosis of heart failure unlikely.
We can conclude that the assessment of plasma NTproBNP level is a relatively simple test which can emerge as a better marker for the assessment of both heart failure severity and risk stratification in acute heart failure patients.

\section{Aknowledgments}

The study was supported by the research projects of the Charles University Prague No.MSM0021620817 and MZO 00179906.

\section{References}

1. Bettencourt P, Frioes F, Azevedo A, Dias P, Pimenta J, Rocha-Goncalves F, Ferreira A. Prognostic information provided by serial measurements of brain natriuretic peptide in heart failure. Int J Cardiol. 2004; 93:45-8.

2. Cappellin E, Gatti R, Spinella P, De Palo CB, Woloszczuk W, Maragno I, De Palo EF. Plasma atrial natriuretic peptide (ANP) fragments proANP (1-30) and proANP (31-67) measurements in chronic heart failure: a useful index for heart transplantation? Clin Chim Acta. 2001; 310:49-52

3. Clerico A, Edmin M. Diagnostic Accuracy and Prognostic Relevance of the Measurement of cardiac Natriuretic Peptides: A Review. Clin Chem. 2004; 6:33-50.

4. Cowie MR, Jourdain P, Maisel A, Dahlstrom U, Follath F, Isnard R, Luchner A, McDonagh T, Mair J, Nieminen M, Francis G. Clinical applications of B-type natriuretic peptide (BNP) testing. Eur Heart J. 2003; 24:1710-8.

5. Daly C, Fox K, Henein M. Natriuretic peptides in the diagnosis of heart diseasefirst amongst equals? Int J Cardiol. 2002; 84:107-13.

6. Denus S, Pharand C, Williamson D. Brain Natriuretic Peptide in the Management of Heart Failure. Chest. 2004; 125: 652-668.

7. Devereux RB, Koren MJ, deSimone G, Okin PM, Kligfield P. Methods for detection of left ventricular hypertrophy: Application to hypertensive heart disease. Eur. Heart J. 1993; 14: 8-15.

8. Gardner RS, Ozalp F, Murday AJ, Robb SD, McDonagh TA. N-terminal probrain natriuretic peptide. A new gold standard in predicting mortality in patients with advanced heart failure. Eur Heart J. 2003; 24:1735-43.

9. Guidelines for the evaluation and management of heart failure. Report of the ACC/AHA task force on practice guidelines. J Am Coll Cardiol 1995; 26:1376-98

10. Hall C. Essential biochemistry and pathophysiology of NT-pro BNP. Eur J Heart Failure. 2004; 6: 257-260

11. Hammemer-Lercher A, Neubauer E, Muller S, Pachinger O, Puschendorf B, Mair J. Head-to-head comparison of $\mathrm{N}$-terminal pro-brain natriuretic peptide, brain natriuretic peptide and $\mathrm{N}$-terminal pro-atrial natriuretic peptide in diagnosing left ventricular dysfunction. Clin Chim Acta. 2001; 310:193-197.

12. Ishii J, Nomura $M$, Ito $M$, Naruse $H$, Mori $Y$, Wang JH, Ishikawa T, Kurokawa H, Kondo T, Nagamura Y, Ezaki K, Watanabe Y, Hishida H. Plasma concentration of brain natriuretic peptide as a biochemical marker for the evaluation of right ventricular overload and mortality in chronic respiratory disease. Clin Chim Acta. 2000;301:19-30.

13. Latini R, Masson S, Anand I, Salio M, Hester A, Judd D, Barlera S, Maggioni AP, Tognoni G, Cohn JN; For the Val-HeFT Investigators. The comparative prognostic value of plasma neurohormones at baseline in patients with heart failure enrolled in Val-HeFT. Eur Heart J. 2004; 25:292-9.

14. Maisel A, McCord J, Nowak R, Hollander J, Wu A, Duc P, Omland T et al: Bedside B. type Natriuretic peptide in the emergency Diagnosis of heart failure with reduced or preserved ejection fraction. J AM Coll Cardiol. 2003; 41:2010-7i.

15. Morrison K, Harrison A, Krishnawamy P, Kazanegra R, Clopton P, Maisel A. Utilitity of a Rapid B.-Natriuretic Peptide Assay in Differentiating Congestive Heart Failure from Lung Disease in Patients Presenting With Dyspnea. J Am Coll Cardiol. 2002; 39:202-9.

16. Nieminen M, Bohm M, Cowie M, Drexler H, Filippatos G, Jondeau G, Hasin Y, Lopez-Sendon J, Mebazaa A, Metra M, hodes A, Swedberg K. Exucutive summary of the guidelines on the diagnosis and treatment of acute heart failure. Eur Heart J. 2005, 26: 384-416.

17. Sahn DJ, DeMaria A, Kisso J, Weyman A. The Committee on M-Mode Standardization of the American Society of Echocardiography: Recommendations regarding quantitation in M-mode echocardiography. Results of a survey of echocardiographic measurements. Circulation. 1978; 58: 1072-83.

18. Shimizu H, Aono K, Masuta K, Asada H, Misaki A, Teraoka H. Stability of brain natriuretic peptide (BNP) in human blood samples. Clin Chim Acta. 1999; 285:169-72.

19. Shimizu H, Masuta K, Aono K, Asada H, Sasakura K, Tamaki M, Sugita K, Yamada K. Molecular forms of human brain natriuretic peptide in plasma. Clin Chim Acta. 2002; 316: 129-35. 
20. Shimizu H, Masuta K, Asada H, Sugita K, Sairenji T. Characterization of molecular forms of probrain natriuretic peptide in human plasma. Clin Chim Acta. 2003; 334: 233-9.

21. Tjeerdsma G, de Boer RA, Boomsma F, van den Berg MP, Pinto YM, van Veldhuisen DJ. Rapid bedside measurement of brain natriuretic peptide in patients with chronic heart failure. Int J Cardiol. 2002; 86: 143-9.

22. Valli N, Georges A, Corcuff JB, Barat JL, Bordenave L. Assessment of brain natriuretic peptide in patients with suspected heart failure: comparison with radionuclide ventriculography data. Clin Chim Acta. 2001; 306:19-26.

23. Vorvouri E, Schinkel A, Roelandt J, Boosma F, Sianos G, Bountioukos M, Sozzi
F, Rizzelo V, Bax J, Karvounis H, Poldermans D. Screening for the left ventricular dysfunction using a hand-carried cardiac ultrasound device. Eur J of Heart Failure. 2003; 5:767-774

24. Yamamoto K, Burnett JC, Jougasaki M et al., Superiority of brain natriuretic peptide as a hormonal marker of ventricular systolic and diastolic dysfunction and ventricular hypertrophy. Hypertension. 1996; 28: 988-994

25. Yu CM, Sanderson JE, Shum IO, Chan S, Yeung LY, Hung YT, Cockram CS, Woo KS. Diastolic dysfunction and natriuretic peptides in systolic heart failure. Higher ANP and BNP levels are associated with the restrictive filling pattern. Eur Heart J. 1996; 17:1694-702.

Submitted November 2006

Accepted January 2007

\section{Corresponding author:}

Radek Pudil, M.D., Ph.D., University Hospital in Hradec Králové, 1st Deptartment of Medicine, Division of Cardiology, Sokolská 581, 50005 Hradec Králové, Czech Republic, e-mail: pudilradek@yahoo.com 